\title{
Entre o Observador e o Integrante da Escola de Samba: os Não- Humanos e as Transformações Durante uma Pesquisa de Campo
}

\author{
Between the Observer and the Samba School's Member: Non-Humans and Transformations \\ During a Field Study
}

\author{
César Tureta * \\ E-mail: cesartureta@gvmail.br \\ ESPM e FEI \\ São Paulo, SP, Brasil. \\ Rafael Alcadipani \\ E-mail: rafael.alcadipani@fgv.br \\ FGV/EAESP \\ São Paulo, SP, Brasil.
}

\footnotetext{
* Endereço: César Tureta

Rua Dr. Álvaro Alvim, 123, Vila Mariana, São Paulo/SP, 04018-010.
}

Copyright (C) 2011 RAC. Todos os direitos, até mesmo de tradução, são reservados. É permitido citar parte de artigos sem autorização prévia, desde que seja identificada a fonte. 


\title{
Resumo
}

Nosso objetivo neste artigo é problematizar a fronteira entre a observação participante e a não participante nas pesquisas organizacionais etnográficas, considerando que além de fluida ela nem sempre é controlável na prática de pesquisa. Nesse sentido, a participação direta do pesquisador pode ser algo inevitável e ele pode passar de mero observador, com pequeno grau de participação, a participante diligente das atividades exercidas pelos pesquisados. Utilizaremos como exemplificação a experiência de campo de um dos autores em pesquisa de cunho etnográfico realizada em uma escola de samba do grupo especial da cidade de São Paulo. Partindo das ideias pós-humanistas, que assumem que o mundo social não se limita a interações humanas, mas coexiste com elementos não-humanos, discutimos como o pesquisador, inicialmente observador não-participante, acabou transformando-se em observador participante e membro ativo da organização estudada, por meio da mediação de tais elementos. Concluímos que os não-humanos possuem influência significativa na prática da pesquisa de campo e podem gerar transformações em: (a) mecanismo de observação; (b) coleta de dados e (c) figura do pesquisador. Essas transformações indicam que os pesquisadores da área de administração deveriam considerar com mais atenção a participação desses elementos na prática da pesquisa.

Palavras-chave: observação; etnografia; não-humanos; escola de Samba.

\begin{abstract}
This paper aims to discuss the boundaries between participant and non-participant observation in organizational ethnographic research. We argue that it is difficult to control such a distinction during an ongoing research process. To demonstrate this, we show how the researcher's participation in activities while gathering data may be inevitable and s/he can change from a mere observer to an active participant while in the field. To argue this, we take as an example one of the authors' fieldwork experience in an ethnographic study at a samba school in the city of Sao Paulo. Starting from a post-humanist perspective, which assumes that the social world is not limited to human interactions but coexists with the material elements, we also argue that the researcher, initially a non-participant observer, became a participant observer and an active member of the organization under study through the mediation of non-humans. We conclude that material elements have significant influence during fieldwork and can generate changes in: (a) research procedure, (b) data collection, and (c) how the researcher is perceived by research subjects. This conclusion indicates that management researchers should take the influence of these elements in the research into consideration.
\end{abstract}

Key words: observation; ethnography; non-humans; samba school. 


\section{Introdução}

O método etnográfico é marca registrada na disciplina de antropologia. Seu emprego na administração, porém, é marginal, embora alguns trabalhos realizados em organizações, a partir da abordagem etnográfica, se tenham destacado como, por exemplo, Engineering Culture de Guindon Kunda (1992) e Police Socialization de John Van Maanen (1975). A etnografia se tornou ferramenta atrativa para pesquisadores da área de Estudos Organizacionais, a partir do momento em que o tema cultura organizacional começou a fazer parte da agenda dos acadêmicos desse campo. Esse método é conhecido pela utilização de técnicas de observação, que consiste em ingressar em determinado grupo social ou organização e observar, participando ou não, as atividades desempenhadas pelos sujeitos da pesquisa. A técnica de observação se mostrou um recurso útil para investigações em organizações, mesmo que não acompanhada pelo método etnográfico. Ela foi sistematicamente empregada no famoso experimento de Hawthorne, cujos antropólogos tiveram papel fundamental, apesar de suas observações não serem frequentemente lembradas (Schwartzman, 1993). Mais tarde, Henry Mintzberg, em estudo clássico do papel do gerente, também ficou conhecido por usar a observação para acompanhar o trabalho dos executivos de cinco organizações de diferentes setores, descrevendo o que eles faziam, suas atividades e funções (Mintzberg, 1971).

Ao optar pela técnica de observação, o pesquisador precisa escolher também se fará observação participante ou não-participante. Essa escolha, que depende muito dos objetivos da pesquisa e da natureza do objeto estudado, pode gerar ambiguidades para o pesquisador no campo, já que as fronteiras entre as formas de observação não são exatamente nítidas (Scott, 1972), além de serem difíceis de controlar na prática da pesquisa. E é exatamente essa questão que pretendemos abordar no presente artigo, descrevendo a experiência de campo de um dos autores em uma pesquisa etnográfica. Nesse sentido, nosso objetivo é problematizar a técnica de observação em pesquisas etnográficas, considerando que as fronteiras entre observação participante e não-participante são fluidas e não totalmente controláveis no campo, já que o pesquisador pode transitar de uma para outra, dependendo das contingências durante a prática da pesquisa. Dessa forma, assumimos que existam gradações entre uma e outra e não que elas sejam diametralmente opostas. Além disso, seguindo crescente corrente de estudos que levam em consideração a questão dos não-humanos nas práticas organizativas (ex. Carr \& Downs, 2004; Engeström \& Blackler, 2005), discutiremos como o processo de transformação da observação para a participação no trabalho de campo pode envolver a mediação de elementos nãohumanos. Pretendemos, dessa forma, contribuir com as discussões a respeito das questões metodológicas associadas à etnografia e à análise das organizações.

Para tanto, o artigo está estruturado da seguinte maneira. Após a introdução, abordaremos as principais características do método etnográfico; na sequência, descreveremos as técnicas de observação participante e não-participante. Depois, trataremos da questão dos não-humanos na vida social e na prática da pesquisa. Em seguida, faremos breve caracterização do objeto da pesquisa original e do método utilizado. Posteriormente, descreveremos a experiência de campo, para a seguir discutirmos a prática da observação no trabalho de campo. No final teceremos nossas conclusões e últimas considerações.

\section{A Etnografia}

O emprego do método etnográfico se limitou, durante um período de tempo, muito mais à investigação de comunidades e tribos não ocidentais do que grupos e organizações ocidentais. No entanto, nas décadas de 1920 e 1930, a Escola de Chicago exerceu papel fundamental no estabelecimento da pesquisa qualitativa nos estudos sobre diversos grupos de indivíduos (Denzin \& Lincoln, 2000), abrindo espaço para a etnografia em cenários urbanos, a partir do desenvolvimento de pesquisas nesses contextos (Atkinson, Coffey, Delamont, Lofland, \& Lofland, 2007; Deegan, 2007). Houve, assim, uma preocupação em analisar a vida nas sociedades tidas como modernas, não apenas 
os lugares longínquos e considerados exóticos. Hammersley (1992) observa que a descrição etnográfica geralmente retrata contextos com os quais os leitores possuem pouca familiaridade. Nesse sentido, se torna importante traçar de maneira detalhada por que, como e o que as pessoas fazem.

A etnografia envolve, geralmente,

a participação manifesta ou disfarçada do etnógrafo na atividade das pessoas por longo período de tempo, observando o que acontece, ouvindo o que é dito, fazendo perguntas - de fato, coletando qualquer dado que possa lançar luz nas questões que são foco da pesquisa (Hammersley \& Atkinson, 1995, p. 1),

sendo envolvimento intensivo no campo uma de suas características distintivas (Agar, 1980). Assim, ela está fundamentada em uma experiência de primeira mão do campo pesquisado e está comprometida com a interpretação do ponto de vista dos que são estudados. Como resultado, a etnografia "produz dados empíricos sobre a vida das pessoas em situações específicas" (Spradley, 1979, p. 13).

A abordagem etnográfica se caracteriza pela pluralidade de perspectivas (Atkinson et. al., 2007; Linstead, 1993) e diversidade de definições (Bate, 1997). Apesar da pluralidade, as distintas perspectivas etnográficas compartilham a ideia da importância da experiência direta com determinado contexto cultural ou social por meio da observação (Atkinson et. al., 2007; Rosen, 1991). A observação direta, por um lado, permite ao pesquisador se aproximar o suficiente do objeto de estudo para observar in loco como se desdobra a vida social. Por outro lado, ela requer certo distanciamento, para que o observador não perca o seu olhar crítico (Bate, 1997). Além disso, a técnica de observação pode constituir-se em participante ou não-participante e sua escolha depende da natureza do objeto pesquisado, visto que, em determinadas situações ou relações, a participação ativa do pesquisador se torna inviável ou difícil de ser realizada (Rosen, 1991; Stacey, 1977). No caso de etnografias em organizações, o etnógrafo também se depara com a escolha entre conduzir uma pesquisa como empregado ou membro ativo do grupo (observação participante); ou como observador externo (observação não-participante), que acompanha as atividades dos integrantes da organização, mas não as realiza tal como seus membros. Mas, independentemente da escolha, o observador sempre terá algum nível de participação, seja ela em maior ou menor intensidade. No próximo tópico daremos a definição de cada uma das formas de observação e, na sequência, abordaremos a questão dos nãohumanos na prática da pesquisa.

\section{Observação Participante e Não-Participante}

A técnica de observação pode ser utilizada para a compreensão de diferentes cenários. Segundo Stacey (1977), é possível empregá-la: em cultura estranha à do pesquisador; em subcultura da cultura do pesquisador; ou em sua própria cultura. No primeiro caso, o pesquisador se lança em um meio com hábitos e costumes completamente diferentes do seu. Um caso clássico foi o do etnógrafo Bronislaw Malinowski (1922/1976), que procurou entender o sistema econômico de trocas dos nativos das ilhas Trobriand, do Pacífico Sul. No segundo caso, o pesquisador se insere em grupo de indivíduos que possuem hábitos e costumes bastante peculiares, dentro da própria cultura do observador. Aqui um exemplo seria o trabalho de William Foote Whyte (1955), que estudou um grupo de imigrantes italianos pobres, moradores de bairro em cidade dos Estados Unidos. No terceiro, o pesquisador investiga uma organização ou instituição formal de sua própria cultura, como, por exemplo, uma empresa (Stacey, 1977). Esse foi o caso do trabalho de Gideon Kunda (1992), que buscou entender a cultura organizacional da divisão de engenharia de empresa de alta tecnologia. O nosso trabalho se enquadra no segundo caso.

A observação participante requer do pesquisador um grau significativo de envolvimento direto e conversações com os pesquisados (Clifford, 2008), observando-os na realização de suas rotinas 
diárias, além da manutenção de relacionamento permanente com eles (Emerson, Fretz, \& Shaw, 1995). Nesse tipo de técnica, o pesquisador ingressa no grupo estudado como se fosse membro, e procura realizar as atividades que são desempenhadas pelo grupo, compartilhando ao máximo a vida social daqueles que estão sendo observados. Ao realizar pesquisa de cunho etnográfico, a observação participante pode ou não ser informada aos pesquisados. O pesquisador pode ingressar no grupo social ou organização, assumir posição ou cargo, mas não revelar seus propósitos. Outra opção é inserir-se no grupo e revelar quais são suas intenções, ao mesmo tempo que participa ou trabalha naquele local (Stacey, 1977). Esse é um dos dilemas corriqueiros em pesquisa etnográfica: revelar a identidade de pesquisador ou manter o anonimato. Situações nas quais serão observadas organizações em que ilícitos são praticados ou no caso de estudo de temas como poder e dominação, pode justificar-se a realização de uma pesquisa infiltrada. Já na observação não-participante, o pesquisador se encontra no local onde os pesquisados estão, observa-os, mas não se torna um deles; não ingressa totalmente na vida social dos estudados, a ponto de desempenhar as mesmas atividades que eles. Apesar de que, na observação não-participante, o pesquisador assume postura de apenas observar, invariavelmente ocorrem alterações no comportamento dos indivíduos observados, uma vez que a simples presença do observador em determinado local seria o suficiente para afetar o comportamento deles (Stacey, 1977).

De acordo com Rosen (1991), existem quatro fatores que precisam ser avaliados no processo de escolha entre uma forma de observação ou outra. O primeiro é o conhecimento técnico, que envolve não só a capacidade instrumental de como desempenhar dado trabalho na organização, mas também o envolvimento emocional e social demandado para a execução das tarefas. $\mathrm{O}$ segundo fator diz respeito ao sigilo organizacional relacionado às políticas, diretrizes e decisões da organização, geralmente protegidas pelo seu conteúdo estratégico. Esse conteúdo pode ser de difícil acesso para funcionários médios; dependendo do objetivo da pesquisa, o acesso poderá ser muito útil para a realização do trabalho. O terceiro é a confiança estabelecida entre o pesquisador e seus sujeitos de pesquisa. Quando o observador ingressa como integrante de um grupo, ocupa posição formal e está dentro da organização, ele se torna parte do jogo político; portanto, alguém que não é totalmente confiável por aqueles que eventualmente se encontrem em posições politicamente contrárias ou conflituosas. Pelo contrário, um observador não-participante seria apenas um indivíduo passageiro, à margem dos processos políticos. Por último, há a definição do papel do pesquisador na organização. Ao se tornar membro ativo, o pesquisador se deparará com dois papéis distintos, porém relacionados: trabalhar e coletar dados. Na sua função de trabalhador, ele irá compartilhar com os outros integrantes as obrigações organizacionais, além de ter de executar as atividades formalmente definidas para a sua função. Por outro lado, ele precisará coletar dados e informações que envolvem fazer perguntas sobre aspectos sociais e culturais das relações dos indivíduos, elaborar anotações ao perceber algo relevante e observar atentamente o desdobramento de eventos enquanto trabalha. Essa constante transição de papéis entre membro integrante (insider) e observador (outsider) pode causar confusão e conflito entre o pesquisador e os pesquisados, algo que não aconteceria, ou teria menores implicações, caso o observador fosse não-participante (Rosen, 1991).

No Brasil, alguns pesquisadores utilizaram a técnica de observação, ao realizarem estudos etnográficos. Bresler (1997), por meio de observação participante, estudou os vínculos sociais que são construídos dentro de uma marcenaria e simbolizados na autoridade da figura do pai e na roupa surrada utilizada pelos empregados. Ele discutiu o rito de passagem como elemento constituinte daquela realidade organizacional e questionou a limitação dos estudos sobre cultura organizacional que se restringem à alta cúpula da organização para determinarem os elementos culturais dela. FloresPereira e Cavedon (2009), ao pesquisarem uma livraria, fizeram análise de como a cultura organizacional pode manifestar-se no corpo dos funcionários, ou seja, antes de se tornar uma representação ela seria experimentada nas vivências corporais dos indivíduos: gestos, tom de voz, postura do corpo, durante suas atividades sociais. 


\section{Não-Humanos e a Prática da Pesquisa de Campo}

Os objetos e não-humanos sempre foram tratados de forma marginal pelas Ciências Sociais, uma vez que a separação entre o mundo natural e o mundo social se constituiu em um dos principais empreendimentos da modernidade (Latour, 1994). Nas últimas décadas, porém, um movimento em direção ao reconhecimento de que esses elementos são pertencentes ao domínio social (Rubio, 2005) tem contribuído para inserir os não-humanos como parte da realidade organizacional. As perspectivas que seguem essa linha estão diretamente vinculadas às idéias do pós-humanismo (Haraway, 1991; Schatzki, Knorr-Cetina, \& Savigny, 2001). A partir delas ocorreu uma reconceituação da ontologia do social, não mais limitada à interação dos humanos, mas destes em associação com os não-humanos, dando origem a noções de existindo-com-objetos (Schinkel, 2004) e objetualização (objectualization) (Knorr-Cetina, 1997). Os não-humanos que constituem a vida social dos humanos não se resumem à materialidade no sentido físico do termo, como, por exemplo, uma cadeira, mas compreendem também ampla gama de elementos, desde outras espécies de seres vivos, como cachorros, gatos (Haraway, 2006) e micróbios (Latour, 1988), até entidades espirituais (Callon \& Law, 2003) ou elementos virtuais como a internet (Norén \& Ranerup, 2005). Ao incluirmos os não-humanos na dimensão social, ampliamos a variedade de elementos que serão passivos de análise, quando as ações passam a ser entendidas como resultado da associação entre humanos e não-humanos (Latour, 2005; Law \& Urry, 2004).

Para a melhor compreensão da vida social não podemos separar os elementos (ex. pesquisador, sujeitos de pesquisa e objetos) dos arranjos que eles constituem na prática (Suchman, 2005), pois humanos e não-humanos estão em constante definição, ou seja, adquirem seus atributos, características e identidade, não por causa de uma essência inerente e existente a priori, mas devido às associações que formam com outros elementos nas atividades em que estão engajados (Latour, 1999; Mol, 2002). Em The Pasteurization of France, Bruno Latour (1988) descreve como a figura heroica do pesquisador Louis Pasteur foi construída a partir de suas práticas de pesquisa e associação com outros elementos. Ter-se tornado um mito seria muito menos algo inerente a Pasteur e muito mais "um efeito, um produto de um conjunto de alianças, de materiais heterogêneos" (Law, 1991, p. 12), tais como micróbios, instrumentos de laboratório e colaboradores de pesquisa. Law (1997a), por sua vez, mostra como seu sujeito de pesquisa, um gerente, se torna figura poderosa da organização por meio do efeito de uma rede de relações com subordinados, secretária, computador e relatórios. Já Suchman (2005), em pesquisa realizada na empresa Xerox, retrata como as fronteiras de uma máquina copiadora foram redefinidas na prática da pesquisa e na relação com vários atores dentro da organização, de forma que aquele elemento pudesse transformar-se em um objeto científico susceptível de ser analisado. Assim, os não-humanos podem operar como mediadores, capazes de gerarem transformações, distorções e modificações nos elementos com os quais se relacionam (Latour, 2005). Callon e Law (2003) exemplificam esse processo de transformação, ao abordarem um culto protestante no qual as pessoas se encontram para um ritual caracterizado pelo silêncio, que pode ser quebrado pela palavra de um dos seguidores no momento em que este se sentir inspirado pelo Espírito Santo. Há modificação em um elemento (o seguidor silencioso), quando outro elemento (a entidade espiritual) se associa com aquele e produz o seguidor-que-discursa.

Apesar dos diversos elementos adquirirem determinada estabilidade, tal como o pesquisador que se torna um mito, o gerente uma figura poderosa e a máquina um objeto de pesquisa, pelo menos em princípio, tudo pode ser considerado como incerto e reversível (Law, 1997b, 1999). Dessa forma, as entidades pesquisador, sujeitos de pesquisa e objetos permanecem como tais, na medida em que a relação entre elas e outros elementos continuar estabilizada. Assim, esses termos ou categorias não devem ser utilizados ou assumidos como portando essências a priori, mas analisados a partir das associações que os constituem na prática, como veremos adiante na discussão da experiência de campo relatada.

Uma vez reconhecido que o mundo é heterogêneo, podemos entender como nossas práticas cotidianas, sejam elas gerenciar empresa, participar de culto religioso ou pesquisar escola de samba, só 
existem devido a uma variedade de não-humanos que fazem parte das atividades e as constituem, compondo essas práticas. No que concerne à prática científica e à influência dos não-humanos no trabalho do pesquisador, Michael (2004) mostra, ao descrever um episódio de sua experiência de campo, como o pesquisador pode encontrar-se em meio a um arranjo de não-humanos (tecnologias e animais), compondo o cenário da coleta de dados e afetando diretamente esse processo. O pesquisador se transforma, então, em um coagente heterogêneo, emergente e localmente situado (Michael, 2004). $\mathrm{Na}$ visão de Latour (2001), compreender a realidade dos estudos científicos requer acompanhar com atenção as práticas científicas. E é exatamente o que ele faz em A Esperança de Pandora, ao seguir o trabalho de cientistas naturais na floresta amazônica e mostrar a prática científica desenvolvendo-se não só a partir do trabalho dos pesquisadores, mas principalmente da relação destes com mapas, etiquetas, arquivos, amostra de plantas, equipamentos técnicos, caderno de campo etc. (Latour, $2001)^{(1)}$. A prática da pesquisa está intimamente relacionada com os não-humanos, elementos quase sempre ignorados, que fazem parte do mundo social e contribuem diretamente para a produção/construção de realidades. Como ressalta Latour e Woolgar (1997, p. 61) "os fenômenos dependem do material, eles são totalmente constituídos pelos instrumentos utilizados" (grifo no original).

Os elementos não-humanos, bem como sua coexistência com os humanos são geralmente tratados superficialmente na teoria organizacional (Orlikowski, 2007). Todavia, sua inclusão na análise dos fenômenos e da prática da pesquisa reduz o risco de direcionarmos nossa atenção somente para as pessoas, negligenciando uma variedade de elementos que compõem nossas redes de relações (Czarniawska, 2007) e que auxiliam a constituição da realidade e a produção de significados. Assim como nas Ciências Sociais, porém um pouco mais tarde, tem ocorrido um movimento, na área de Estudos Organizacionais, em direção à consideração de tais elementos no processo organizativo, como podemos observar nas edições especiais de 2004, v. 17, n. 4 do Journal of Organizational Change Management (Downs \& Hagemeijer, 2004) e de 2005, v. 12, n. 3, da Organization (Blackler \& Engeström, 2005). No Brasil, esse movimento ainda é embrionário, embora alguns autores já sinalizem na mesma direção, como por exemplo, Tureta e Alcadipani (2009), ao apresentarem uma discussão sobre a importância da inclusão dos objetos e não-humanos na análise de organizações brasileiras. Nosso foco neste artigo, contudo, não é o da participação dos não-humanos no processo organizativo, mas na constituição da prática da pesquisa e da relação do pesquisador com seu objeto de estudo por meio da observação, como veremos nos próximos tópicos.

\section{O Método}

O objeto da pesquisa que originou este trabalho é uma escola de samba do grupo especial da cidade de São Paulo. Essa agremiação é considerada uma das mais antigas e tradicionais da capital paulista, além de possuir vários títulos de campeã. Assim como boa parte das escolas de samba da cidade, ela também surgiu a partir de um Cordão Carnavalesco de um bairro da capital. Tais organizações podem ser definidas como associações recreativas e musicais ou sociedades civis de cultura e lazer sem finalidades lucrativas, cujo objetivo principal é se apresentarem no carnaval (Goldwasser, 1975; Queiroz, 1999). Para este artigo, porém, delimitamos como unidade de análise a figura do pesquisador e sua relação com os elementos humanos e não-humanos durante a prática da pesquisa de campo no evento do desfile carnavalesco do ano de 2010. Os dados serão apresentados em uma narrativa em primeira pessoa, com enredo estruturado (Clifford, 2008), para destacar a presença do pesquisador no campo.

Os primeiros contatos com a escola ocorreram no final de 2008. No entanto, comecei a pesquisa de campo em meados de setembro de 2009, indo até o término do carnaval, em fevereiro de 2010. Para a realização da pesquisa eu não ingressei na escola como membro de função formalmente definida. Assim, não assumimos que a pesquisa tenha sido projetada na direção de uma observação participante, embora em diversas situações, não só na relatada aqui, eu acabei participando ativamente de algumas atividades, como se fosse integrante da agremiação. Vale ressaltar: apesar de assumir a postura de 
observador não-participante, é inevitável a existência de algum grau de participação, pois como destaca Scott (1972), a dicotomia atribuída aos diferentes mecanismos de observação é na realidade um continuum. $\mathrm{O}$ que tinha sido acordado, inicialmente, é que eu poderia acompanhar as principais atividades do processo de produção do desfile do ciclo 2009/2010. Assim, diferentemente de boa parte das pesquisas etnográficas, não tive grandes problemas em ter acesso ao campo. Pelo contrário, obtive o aceite no primeiro contato com o diretor de harmonia ${ }^{(2)}$, que se prontificou a colaborar e permitiu minha presença em vários lugares onde se desdobravam as práticas de organização do desfile. No final do trabalho de campo, desfilei na escola como integrante da Alegoria ${ }^{(3)}$.

Foram seis meses de observações, durante as quais eu fazia anotações em caderno de campo e, posteriormente, as expandia no editor de texto Word. Nesse período participei de reuniões do setor de harmonia, frequentei os ensaios na quadra da escola, fiz visitas ao barracão durante o dia (local este restrito até para muitos integrantes da própria escola e preservado ao máximo, a fim de se manter sigilo total); acompanhei os ensaios técnicos no sambódromo e a retirada dos carros alegóricos do barracão durante a noite e a madrugada, além de desfilar pela agremiação no dia da apresentação na avenida. A experiência relatada neste artigo envolve a minha interação com os integrantes da escola, desde a concentração na quadra da agremiação, passando pela concentração do sambódromo ${ }^{(4)}$ até o desfile propriamente. Nesse dia fiquei no campo da meia noite até às 9 h30 da manhã. Durante esse tempo, três momentos marcaram a relação do pesquisador com os humanos e não-humanos envolvidos no desfile, ilustrando a tênue fronteira entre observação participante e não-participante e o processo de transformação mediado por elementos não-humanos.

Para o desenvolvimento deste artigo, as notas de campo referentes ao dia do desfile foram organizadas e analisadas a partir de várias leituras sistemáticas de seu conteúdo. Com isso, foi possível identificar os três momentos mencionados e a participação dos não-humanos em cada um deles. Uma vez identificados, foi construída uma narrativa linear dividida pelo tempo. A divisão linear dos diferentes momentos teve fim meramente didático, no intuito de facilitar a compreensão do evento que será apresentado nos tópicos a seguir. O nome da agremiação, bem como de seus integrantes serão omitidos com intuito de preservar suas identidades. Minha informante principal será tratada pelo nome fictício de Vitória.

\section{A (Im)possibilidade do Mero Observador}

\section{“Vigia essas sacolas pra mim?"}

O ponto de encontro no dia do desfile para todos os integrantes da escola e foliões foi a quadra da agremiação. De lá vários ônibus seguiriam em direção ao sambódromo. Eu havia combinado de encontrar minha informante (Vitória, integrante da harmonia) na quadra por volta da meia-noite. Dias antes, ela tinha-me orientado a não levar minha bolsa com meu material de trabalho (que continha máquina fotográfica, caderno de campo e canetas), pois eu poderia perdê-la no tumulto da concentração. Portanto, nesse dia, fui apenas com a roupa do corpo (uma calça jeans, tênis branco e camisa de malha branca) e minha identidade, celular e algum dinheiro no bolso. Cheguei no horário marcado. A rua estava repleta de pessoas, muitas delas com suas fantasias nas mãos e outras parcialmente fantasiadas. A movimentação era intensa: muitos carros, ônibus e pessoas circulando pelas ruas próximas. Avistei vários harmonias ${ }^{(5)}$ andando de um lado para o outro com papéis nas mãos e conversando com outros integrantes da escola. Alguns deles gritavam, outros gesticulavam. Pareciam ajustar detalhes para o desfile. Fui até a quadra à procura da Vitória. Lá havia vários foliões fantasiados, aguardando o horário da partida. Como não a encontrei, saí e voltei para a rua, onde fiquei conversando com alguns harmonias em frente à quadra. Minutos depois, a Vitória chegou com sua filha, que era integrante da Alegoria. Vitória carregava duas pastas nas mãos, duas sacolas com alguns pertences e um cabide com as roupas para o desfile. Inicialmente eu desfilaria com a roupa de merendeiro $^{(6)}$, como combinado semanas antes com um dos harmonias. A roupa seria entregue a mim na hora do desfile. 
Enquanto conversávamos na rua, a Vitória precisou resolver algumas coisas. Ela se dirigiu a mim e disse: "Vigia essas sacolas pra mim?" e nos entregou (para mim e para a filha dela) as pastas, as sacolas e o cabide com as roupas do desfile. Dali em diante até a concentração, exerci o papel de guardião de sacolas. Por volta das 1 h15 a Vitória voltou e disse que já iríamos pegar o ônibus para o sambódromo. Antes de embarcar, um harmonia passou por mim e me entregou duas grandes sacolas com sandálias e disse que elas deveriam ser distribuídas para as composições ${ }^{(7)}$ de um dos carros alegóricos. Fiquei com várias sacolas na mão. Passei as mais leves para a filha da Vitória e fiquei com as duas sacolas de sandálias, bastante pesadas. Em seguida, entramos no ônibus e fomos ao sambódromo.

O ônibus parou em uma área próxima ao sambódromo destinada para o desembarque. Durante o trajeto daquele local até a concentração fui carregando as sacolas com sandálias; estas, além de pesadas, não tinham boas alças. Vitória precisou parar em um hotel perto do sambódromo para saber como estavam as destaques ${ }^{(8)}$ dos carros alegóricos que se hospedaram lá. Eu a acompanhei, enquanto os demais seguiram em frente. Depois de uns alguns minutos de caminhada, chegamos à área de concentração. A movimentação de pessoas era grande e tive dificuldade de saber como me portar, onde ficar e o que fazer. A Vitória ficou sabendo que sua filha substituiria uma composição de carro que havia faltado. Ela logo se dirigiu a mim e disse: "Qualquer coisa você sai com a camisa de Alegoria da minha filha". Sorrindo ela completou: "Não se assuste a camisa é unissex!". O uniforme de Alegoria é uma camisa preta (escrito Alegoria nas costas), calça de linho preta e sapato preto. Enquanto a Vitória circulava de um lado para outro e conversava com os harmonias, eu fiquei em pé em frente a um dos carros alegóricos, vigiando as sacolas. Ter de vigiar as sacolas limitou meu campo de observação, pois eu não poderia circular livremente pela concentração, já que a qualquer momento alguém poderia precisar delas. Passado alguns minutos, um grupo de harmonias, incluindo a Vitória, se reuniu próximo de onde eu estava e começaram a conversar. Escutei alguém falar dos calçados. Dirigi-me para perto da Vitória e entreguei-lhe as sacolas.

Poucos minutos depois, saindo por entre os carros, avistei a filha da Vitória, devidamente fantasiada de composição, caminhando em minha direção. Ao chegar perto de mim, ela solicitou minha ajuda para colocar um adereço da fantasia em sua cabeça. Muito desajeitado, tive dificuldades em amarrar a peça sem puxar e prender seu cabelo no elástico. Durante as minhas desastrosas tentativas, ela reclamou umas duas ou três vezes com um tom de brincadeira: "Assim você vai me deixar careca!". Fiquei um pouco desconcertado por não conseguir fazer algo tão simples, e disse-lhe: "É, eu não tenho jeito pra essas coisas...". Como eu não conseguia amarrar, pedi a Vitória, que felizmente estava passando, para amarrar a peça. Com o mesmo bom humor da filha, ela brincou: "O sem jeito mandou lembranças!". Serviço feito, cada uma saiu para um lado. Diferentemente das duas, eu ainda estava sem a roupa para desfilar. E como se não bastasse, o harmonia que havia ficado de trazê-la para mim se aproximou de onde eu estava e disse que a roupa de merendeiro tinha acabado. Naquele momento imaginei que eu não conseguiria desfilar, o que seria muito frustrante. Dirigi-me até a Vitória e a informei da falta da roupa. Ela pegou a camisa de Alegoria da filha, entregou-me e disse para eu vestir: "Agora precisamos arrumar uma calça e um sapato pra você. Não se preocupe, sem desfilar você não fica!". Achei que eu me tinha livrado das sacolas, mas junto com a camisa, a Vitória me entregou outra sacola com algumas peças da fantasia de um destaque importante da escola: "Não deixe essas coisas daí sumirem, hein!" Além disso, outra harmonia pediu que eu cuidasse de duas grandes sacolas verdes: "Dá uma olhadinha nessas sacolas ai", disse ela. Uma delas continha os calçados dos componentes do carro abre-alas e servia também para guardar os pertences deles. A outra seria usada para guardar os pertences dos harmonias, além de conter alguns materiais (tesoura, fitas, linhas, cordões/barbante), que poderiam ser usados em alguma eventualidade. Novamente fiquei preso às sacolas e não pude sair daquele local próximo ao carro abre-alas.

\section{"Ajuda as meninas ali com a fantasia"}

Com a camisa de Alegoria vestida, continuei exercendo minha função de guardião das sacolas. Porém, um detalhe interessante foi que, após vestir a camisa, minha condição de pesquisadorobservador se alterou significativamente. Se até então eu somente ajudava em algumas atividades 
básicas (vigiar e carregar sacolas), quando era explicitamente solicitado, recebendo orientações sobre o que fazer, agora nova figura parecia ganhar forma mais claramente, com novas atribuições e responsabilidades, não só recebendo orientações, mas as fornecendo também. Essa figura seria a do pesquisador-integrante da escola de samba. Como as composições de carro e alguns membros da escola não me conheciam, quando me viam, pediam que eu realizasse algumas tarefas. Um membro da diretoria, que não me conhecia, passou perto de mim e disse: "Ajuda as meninas ali com a fantasia". Hesitei por um momento e fiquei sem saber o que fazer. Olhei para os lados na esperança de passar um harmonia, de forma que eu pudesse chamá-lo. Mas, na correria em que estava, era difícil encontrar alguém disponível. Havia algumas composições de carro alegórico, que estavam com problemas para ajustar as fantasias. Uma delas, segundos depois, olhou para mim e disse: "Me ajuda a amarrar isso aqui na minha perna?". Eu hesitei novamente. Mais uma vez olhei para os lados e me frustrei ao não identificar alguém que pudesse fazer aquilo por mim. Fiquei bastante desconfortável com aquela situação.

Coloquei as sacolas em um canto seguro e um pouco reticente fui ajudá-la a arrumar as tornozeleiras, uma peça da fantasia que ficava amarrada da canela até o tornozelo. Eu não fazia a mínima ideia de como amarrava, já que tinham vários furos para a entrada de uma espécie de cordão/barbante que deveria se entrelaçar na altura da panturrilha. Para a minha sorte, uma composição, que vestia a mesma fantasia e viu minha dificuldade, me mostrou como a dela estava amarrada e como eu deveria prender na perna. Contudo, o cordão era único e deveria ser cortado para poder amarrar nas duas pernas. Não dava para cortar com a mão, pois ele era espesso. Lembrei de uma tesoura que os harmonias usavam e que era guardada na sacola verde. Fui até a sacola, mas para meu azar não a encontrei. Voltei até a componente, meio desconcertado e disse que a tesoura não estava lá e que eu iria ver se achava com alguém. Nesse momento, uma harmonia chegou próximo a mim e eu solicitei ajuda. Ela pediu que eu segurasse e esticasse o cordão com as duas mãos, tirou do bolso um isqueiro e com o fogo cortou o cordão ao meio. Esse improviso me salvou, pois estava com receio da componente do carro começar a se irritar com a demora e se dirigir a mim de forma agressiva. Como a Vitória já me havia dito que em carnavais anteriores alguns componentes se dirigiam aos harmonias de maneira ofensiva por causa de problemas com as fantasias, eu pensava nisso o tempo todo e procurava não cometer nenhum deslize. Após cortar o barbante, consegui amarrar as tornozeleiras.

Depois disso, imaginei que tudo estivesse resolvido, mas a componente ainda precisava que amarrasse um adereço da fantasia em sua cabeça, coincidentemente, o mesmo da filha da Vitória. Na hora hesitei novamente, pois lembrei que puxei o cabelo da filha da Vitória algumas vezes e não consegui amarrar. E agora eu não podia fazer o mesmo, já que poderia ser repreendido por ela de forma ríspida. Mas também eu não podia negar, afinal de contas, para ela, eu era um integrante da escola e essa era a minha função. Peguei a peça e a primeira coisa que eu disse foi: "Se eu puxar seu cabelo você me avisa tá?". Com muito cuidado puxei o elástico até a nuca dela e consegui amarrar. Ao terminar e ter a sensação de dever cumprido, ela me perguntou: "Eu tô sem o chinelo azul" (acessório da fantasia), "eu posso desfilar com esse aqui mesmo?". Olhei para os pés dela e ela estava com uma sandália prateada, bem diferente daquela que fazia parte do figurino. Não avistei nenhum harmonia disponível para tirar essa dúvida, que eu não sabia solucionar. Fiquei confuso, não sabia o que dizer. Eu não podia falar que sim, porque cada fantasia tem suas peças e uma peça diferente poderia implicar perda de pontos, caso algum jurado identificasse esse detalhe. Não respondi nada de imediato, fiquei alguns segundos pensando e lembrei novamente que os chinelos se encontravam dentro da sacola verde. Fui até lá e retornei frustrado outra vez, pois os chinelos tinham acabado. Nesse momento a Vitória passou e eu perguntei o que fazer. Ela disse para mulher ficar com aquela sandália até conseguirem os chinelos. A mulher me agradeceu e se dirigiu para o seu lugar no carro.

Apesar de já estar com a camisa de Alegoria, ainda faltavam a calça e o sapato preto. Questionei a Vitória sobre isso. Ela, então, pegou a calça preta que seria usada pela sua filha, arrumou uma bota preta de soldado, que fazia parte da fantasia dos componentes de um dos carros e que havia sobrado e me entregou. Embora a calça tenha ficado justa e a bota machucando meus pés, eu estava enfim uniformizado. Troquei-me rapidamente atrás de um carro alegórico e fui para onde se encontrava o carro abre-alas. As sacolas verdes, com os pertences dos componentes de carro e dos harmonias foram 
amarradas e colocadas em um local não visível dentro do abre-alas. A bateria já fazia seu aquecimento. As alas estavam todas postadas de frente para a avenida nos seus devidos lugares e os carros posicionados para entrarem entre as alas. $\mathrm{O}$ abre-alas foi o mais difícil de posicionar, uma vez que ele continha três partes que se engatavam umas nas outras. Depois de muito esforço, gritaria e palavrões, as três partes foram encaixadas e alinhadas corretamente. Já preparando para entrar na avenida, uma componente de carro me chamou e perguntou se ela poderia sambar em cima do carro sem correr o risco de quebrar a plataforma e ela cair. Hesitei na resposta por ainda estar inseguro em relação ao meu papel, embora já estivesse exercendo a função de Alegoria. Como eu não sabia se o local era firme, coloquei a mão na plataforma e pressionei para baixo com força. Parecia seguro, então eu disse: "Pode sambar, só você não deve pular...".

\section{"Fica ai e coloca os merendeiros pra empurrar"}

Ainda na concentração, um Alegoria disse-me que ficasse no final do carro abre-alas orientando os merendeiros: "Fica aí e coloca os merendeiros pra empurrar". Esse momento foi o de maior tensão para mim, pois eu teria de interagir com os merendeiros, dando-lhes orientações. Era uma responsabilidade que eu não me sentia à vontade em assumir. Fui até o final do carro e disse a uma Alegoria o que o outro integrante da escola me tinha solicitado e ela disse: "Tudo bem pode deixar, há gente que pode ficar ali”. Senti-me aliviado e voltei à parte central do abre-alas. Fiquei ali aguardando o momento da entrada na avenida. A bateria já havia feito seu aquecimento e começava a tocar o samba-enredo. Antes mesmo de o desfile começar, a empolgação dos integrantes da escola era contagiante. Todos cantavam com muita disposição e pareciam eufóricos. Os meus sentimentos se confundiam: ansiedade, nervosismo e emoção.

Quando a sirene do sambódromo tocou, por volta das 6h45, com uma hora de atraso, e a escola iniciou seu desfile, a empolgação se multiplicou e o samba-enredo passou a ser cantado por todos com mais animação. Era possível ver, da concentração, que o público também estava muito animado na arquibancada. Os merendeiros faziam seu trabalho de empurrar e os harmonias cadenciavam a velocidade. Tudo corria bem até que, de repente, próximo do local onde eu estava, onde os merendeiros seguram o varal ${ }^{(9)}$ para empurrar, o eixo que ligava uma parte do carro a outra quebrou. Houve correria e desespero geral. Foi um momento de muita tensão. Rapidamente os membros da escola e os merendeiros procuraram um jeito de colocar o eixo no lugar, algo que não foi fácil e demorou alguns minutos. Quando eles conseguiram, os harmonias então fizeram sinal e gritaram desesperadamente para que o carro fosse empurrado o mais rápido possível, de forma que pudesse alcançar a ala da frente que já estava quase toda na avenida. Nessa hora, não só os merendeiros empurraram, mas vários harmonias também o fizeram. Dessa vez sem hesitar, eu corri, arrumei um espaço na lateral do carro e comecei a empurrar também. Felizmente conseguimos fazer o carro aproximar-se da ala antes da linha amarela ${ }^{(10)}$ e a escola entrou na avenida sem buraco ${ }^{(11)}$. Ali comecei a me sentir um pouco mais integrante da escola.

Eu me posicionei entre a primeira e a segunda parte do carro abre-alas. Naquele local eu poderia circular por uma faixa de uns 50 metros na avenida para observar os harmonias. Muita gente tirava fotos, fazia filmagens e acenava para os componentes da agremiação. Na frente do carro abre-alas ficava um harmonia, orientando os demais que vinham logo atrás. Juntamente comigo havia outro Alegoria. Como os merendeiros não me conheciam, eles ficavam olhando para mim, aguardando as orientações sobre o que fazer. Quando o harmonia da frente fazia os sinais de orientação com as mãos, ele também olhava para mim esperando que eu orientasse os merendeiros. O Alegoria que estava ao meu lado pediu que eu assumisse a função: "Fica dando orientação para os merendeiros aqui". Sentime desconfortável em fazer essa função, já que, de fato, eu não era integrante da escola e não pretendia interferir diretamente no trabalho dos harmonias e Alegorias. Por outro lado, achei que não deveria negar a tarefa que me foi dada e, além do mais, exercer aquela atividade me pareceu algo desejável e esperado pelos harmonias e Alegorias, que me olhavam aguardando uma (re)ação. Quando percebi que até os harmonias que me conheciam se comunicavam comigo como se eu fosse integrante da escola, resolvi incorporar de vez o espírito de integrante da agremiação e fazer o meu papel de 
Alegoria. Contudo, exercer essa função limitou meu campo de observação na avenida, pois agora eu não poderia mais sair dali.

Apesar de entrar no espírito de integrante da escola, no início eu coordenava os merendeiros de forma um pouco acanhada, fazendo gestos com as mãos e passando as informações sobre qual deveria ser o ritmo do carro. Esses gestos são códigos usados pelos harmonias para se comunicarem sobre a velocidade que o carro deveria ser empurrado, se deveria parar ou retomar o movimento. Aos poucos eu fui me sentindo mais à vontade. Se o sinal enviado era de empurrar rápido, primeiro eu me dirigia aos merendeiros com um tom de voz mais elevado do que quando era para empurrar devagar; simultaneamente eu batia a palma das mãos com força e gritava: "Vamos lá, galera, vamos empurrar!". Na concentração e no início do desfile observei que era assim que os harmonias e os Alegorias se dirigiam a eles, quando era necessário o movimento rápido. Procurei fazer de maneira semelhante. Nas primeiras vezes que foram emitidos os sinais para empurrar rápido eu só gritava e batia as mãos, mas fui percebendo que quando eu, além de gritar, empurrava também, os merendeiros faziam mais força e empurravam mais rápido. Ao me verem empurrando, fazendo uma função que em princípio não seria minha e me rebaixando de status $^{(12)}$, parecia que eles se sentiam na obrigação de se dedicar mais. Então, passei a empurrar também, quando era preciso acelerar.

Nos momentos em que o carro parava, por ter-se aproximado demais da ala da frente, os merendeiros saíam de sua posição inclinada, segurando o varal, e acenavam para o público. Os harmonias também faziam o mesmo. Esse era o momento no qual se podia curtir o carnaval, embora essa distração não fosse desejável durante o desfile ${ }^{(13)}$. Eu também acabei virando-me para o público algumas vezes, quando o carro estava parado. Em uma delas, fiquei tão vislumbrado com a empolgação das pessoas na arquibancada, que não percebi que já estavam fazendo sinal para que o carro voltasse a andar. Era difícil manter-se totalmente alheio à energia que vem do público. Depois dessa distração, passei a me concentrar mais no trabalho e durante todo o desfile fui exercendo minha função de coordenação dos merendeiros, fazendo gestos com as mãos e falando, algumas vezes em tom mais elevado, para indicar o que eles deveriam fazer. Da metade do desfile para frente, me senti mais confortável com o meu papel. A tensão passou e consegui relaxar. Eu recebia as informações por meio dos códigos e passava a orientação para os merendeiros. Fiz isso durante todo o desfile.

Quando chegamos à área de dispersão ${ }^{(14)}$, logo que o carro abre-alas parou, a Vitória me pediu que subisse nele e pegasse as sacolas. Peguei-as e fui para um canto juntamente com uma integrante da Alegoria e a filha da Vitória. Ficamos ali devolvendo os pertences dos componentes de carro. Só na dispersão eu senti o desconforto da roupa e da bota. Troquei-me rapidamente e fiquei aguardando, junto com os outros harmonias, o ônibus que nos levaria até a quadra da agremiação. Na volta, dentro do ônibus, muitos pareciam bastante cansados, também eu. Outros se mostravam aliviados por terem cumprido o dever, enquanto outros ficavam indignados com os problemas que ocorreram no desfile. Ao chegar à quadra, uma harmonia me perguntou o que eu achei da experiência. Eu lhe disse que havia gostado muito e que a emoção na avenida tinha sido grande. Comentei ainda que foi uma experiência única, principalmente por ter sido a primeira vez que desfilei em escola de samba. Ela então falou que eu poderia ter-me divertido mais, se "não tivessem te dado uma responsabilidade de Alegoria, que não era sua. Foi sua primeira vez na avenida e já te colocaram para trabalhar". Eu respondi dizendo que não me importei com isso e que até achei interessante, pois havia sido muito proveitoso para minha pesquisa. Despedimo-nos e fomos embora.

\section{Discussão e Problematização da Prática da Observação no Trabalho de Campo}

O recurso da descrição dos eventos por meio da linha do tempo teve o intuito meramente didático, como já mencionamos. Todavia, invariavelmente ele cria uma imagem de linearidade em processo que não é linear, muito menos mecânico, com etapas bem definidas. Além do mais, as transformações que apresentamos e discutiremos agora não são independentes. Entendemos que elas se iniciam no momento em que o pesquisador entra em contato com seu objeto de pesquisa e continua 
nos seis meses seguintes de investigação, durante os quais ele se relacionou com os pesquisados, participando de reuniões, ajudando na retirada de carros alegóricos do barracão, lanchando com eles em postos de gasolina, frequentando os ensaios na quadra e no sambódromo. O evento relatado, no entanto, reuniu uma série de elementos humanos e não-humanos, que permitiram que essas transformações se apresentassem de maneira mais evidente. Assim, os três momentos apresentados podem ser entendidos como processo gradativo de transformação do pesquisador no campo que, em princípio, participaria do desfile apenas como observador privilegiado, acompanhando a agremiação dentro da avenida. O que era para ser mais um dia de observação se configurou em relação que vai além da condição de observador externo.

Como destaca Latour (2005), alguns elementos podem operar como mediadores, transformando e modificando aqueles que entram na relação com eles. Nesse sentido, os não-humanos, sacolas e camisa, promoveram três transformações simultâneas durante a prática desta pesquisa de campo, em relação ao trio seguinte: (a) mecanismo de observação; (b) coleta de dados; e (c) figura do pesquisador. Quanto ao mecanismo de observação, houve uma mudança da observação nãoparticipante para a observação participante, sem que isso tenha sido controlado pelo pesquisador. $\mathrm{O}$ que fora planejado e combinado com os pesquisados era que o pesquisador seria mero observador, não-participante, ou seja, permaneceria no local onde o grupo estudado se encontrava, para observá-lo sem ingressar como membro da organização (Stacey, 1977). No entanto, gradualmente, o pesquisador passou a realizar as mesmas atividades dos pesquisados; aos poucos, foi ocorrendo uma transição no continuum dos mecanismos de observação (Scott, 1972). O mais interessante é que essa transição, além de ter ocorrido de forma natural, parecia desejável por parte dos pesquisados. Isso pode ser constatado nas passagens em que o pesquisador foi solicitado a realizar algumas atividades, como se fosse integrante da escola, num primeiro momento carregando e vigiando as sacolas e, depois, fornecendo apoio às composições de carros e orientando os merendeiros. Alguns harmonias que fizeram essas solicitações sabiam que o pesquisador estava ali apenas para realizar seu trabalho de observação e não para trabalhar pela escola. Independentemente disso, nenhum deles se pronunciou para dizer que não era necessário assumir essas atividades. Assim, a camisa de Alegoria dificultava o pesquisador de se posicionar como observador externo. Com ela no corpo, ele era constantemente solicitado a participar das tarefas que qualquer Alegoria deveria fazer.

A outra transformação refere-se aos direcionamentos na coleta de dados. Mediado por esses não-humanos, a possibilidade de circular livremente, tanto pela concentração quanto pela avenida, ficou limitada. Na concentração o pesquisador só conseguia observar aquilo que estava ao seu redor, sem poder deslocar-se para investigar a movimentação dos demais harmonias da escola e da organização dos outros carros alegóricos, pois precisava vigiar as sacolas. A camisa, por sua vez, restringiu a livre circulação do pesquisador, na medida em que ele tinha que ajudar as componentes de carro com as suas fantasias na concentração e, depois na avenida, coordenar os merendeiros em dado setor. Como destaca Schinkel (2004), a função de um não-humano, na prática, tem um caráter contingencial e, embora não se reduza àquela atribuída por outra entidade, em uma dada situação o define e interfere naquela prática específica. Para o pesquisador, naquele momento, a sacola e a camisa ganharam o atributo de "intrusos" e exerceram a função de direcionadores da coleta de dados, limitando sua atuação como observador. Porém, para os integrantes da agremiação, a sacola tinha a função de acomodar as sandálias e guardar os pertences dos harmonias e das composições de carro alegórico, e a camisa de identificar um Alegoria e diferenciá-lo de outros integrantes. Apesar do papel dos não-humanos na produção de dados de pesquisa ser normalmente oculto (Michael, 2004), não podemos separá-los dos arranjos sociais dos quais fazem parte na prática (Suchman, 2005), pois um olhar mais atento pode revelar que eles são capazes de direcionar o pesquisador para eventos ou situações específicas. Essa sempre foi tarefa atribuída apenas aos informantes. Assim como os pesquisadores aprendem a lidar com seus informantes, aprender a lidar com os não-humanos, na prática da pesquisa, se torna um desafio para os praticantes da pesquisa de campo.

A terceira transformação diz respeito à figura do pesquisador. A camisa de Alegoria serviria em princípio somente para possibilitar que ele acompanhasse o desfile na avenida. Porém alguns elementos possuem "propriedades miraculosas" (Latour, 1994, p. 110); estão em constante definição e 
seus atributos e características são resultado da associação com outros elementos humanos e nãohumanos (Latour, 1999; Mol, 2002). Nesse sentido, a camisa de Alegoria atuou de forma a configurar o pesquisador em nova entidade, como agente localmente situado (Michael, 2004). Essa nova figura não é mais apenas observador de instituição de ensino superior que realiza a sua pesquisa de doutorado. Tal como a entidade espiritual retratada por Callon e Law (2003), a camisa de Alegoria, em associação com o observador, gera modificações e produz agora o pesquisador-integrante da escola de samba, que desempenha as atividades dos membros da agremiação, orientando os merendeiros, auxiliando os componentes de carros alegóricos e interagindo com os harmonias por meio de códigos. Nessa mudança, o pesquisador enfrenta alguns dilemas e pode ver-se diante de decisões que impliquem sérias consequências para os sujeitos pesquisados, como, por exemplo, quando foi questionado por uma componente de carro se poderia sair com sandálias diferentes daquelas que compunham seu figurino. Era pequeno detalhe, mas com significativo potencial de prejudicar a nota do quesito fantasia ${ }^{(15)}$. E, devido à maior competitividade das escolas nos carnavais recentes, poucos décimos são suficientes para tirar o título de uma escola de samba. Por um lado, o pesquisador percebeu, a partir de um determinado momento, que era desejável e esperado por alguns harmonias a sua participação e a recusa poderia gerar algum tipo de desconforto na relação com os pesquisados; mas, por outro lado, se ele não tivesse conhecimento sobre o carnaval e a sistemática de avaliação do desfile poderia trazer danos ao objeto de estudo, caso uma decisão equivocada fosse tomada por alguém que formalmente não poderia tomá-la. Vale frisar, ainda, que a constituição do sujeito, como pesquisador, sempre foi intermediada por não-humanos, como roupas, gravadores digitais, canetas, cadernos de campo etc.

Rosen (1991) alerta para possível conflito entre pesquisador e pesquisados, quando o primeiro participa ativamente das atividades na organização em estudo e precisa transitar entre observador externo e trabalhador. Ao contrário disso, no nosso caso o dilema não foi com o outro, mas com o próprio pesquisador, que teve de lidar com as três transformações anteriormente mencionadas. Ao invés de confusões e conflitos com os sujeitos de pesquisa, estes, na verdade, pareciam demonstrar, pelas atitudes e conversações, interesse que o pesquisador exercesse os dois papéis, como pode ser percebido nas falas: "Não se preocupe, sem desfilar você não fica!" e "Fica aí e coloca os merendeiros para empurrar". A primeira fala é da informante, que se esforçou para colocar o pesquisador na avenida, mesmo com o imprevisto da falta de roupa de merendeiro, de forma que ele pudesse observar o trabalho dos harmonias de perto e, assim, conseguir realizar sua pesquisa de campo como havia planejado. A segunda fala é de um Alegoria que pediu ao pesquisador que orientasse os merendeiros de um dos carros alegóricos, demonstrando que seria importante que ele, pesquisador, assumisse uma função, cujo trabalho teria de ser realizado por alguém. Essas passagens ilustram a transição entre os níveis de participação do pesquisador e como as duas figuras do observador não-participante e participante coexistem e se transformam, na prática da pesquisa. Essas transformações, são mediadas pelos não-humanos, que se associam ao humano (pesquisador); como argumenta Latour (2005), o processo de ordenação social e, também da prática de pesquisa, envolvem vários elementos como, por exemplo: sacolas, camisa, chinelos, códigos com as mãos, informante, outros integrantes da escola, componentes de carro etc.

\section{Conclusões}

A prática da pesquisa de campo em organizações, com o emprego do método etnográfico, faz emergir uma série de questões concernentes à relação do pesquisador com seu objeto de estudo. Neste trabalho, procuramos problematizar a técnica de observação, por excelência um recurso da abordagem etnográfica, e a participação dos não-humanos na prática da pesquisa, tomando como exemplo a experiência de campo de um dos autores em uma pesquisa etnográfica realizada em uma escola de samba do grupo especial da cidade de São Paulo. A técnica utilizada se mostrou não controlável na pesquisa relatada, transitando de observação não-participante a participante, sem que isso tivesse sido planejado. Mesmo fazendo sua escolha no início da pesquisa, no campo o pesquisador se deparou com 
fronteiras fluidas que separam esses dois mecanismos de observação, fazendo com que seja difícil definir precisamente onde um começa e o outro termina.

Na nossa discussão abordamos como os não-humanos possuem participação ativa na prática da pesquisa, exemplificando por meio de três transformações pelas quais o pesquisador passou no campo. Concluímos que esses elementos sejam capazes de transformar: (a) a figura do pesquisador, no sentido de ele não ser visto mais apenas como observador, mas integrante da organização, sendo isso até desejável pelos sujeitos da pesquisa; (b) o mecanismo de observação, que pode transitar de uma forma para outra sem que o pesquisador tenha total controle da situação; e (c) os direcionamentos na coleta de dados, que podem ser modificados e restringir o campo de observação, conduzindo o pesquisador para um evento ou para outro de maneira a limitar seu poder de decisão sobre o que e onde observar. Essas transformações evidenciam ainda a existência de múltiplas realidades (ver Law, 2004; Mol, 2002), em que o mesmo objeto (o pesquisador) se apresenta de forma múltipla: observador nãoparticipante, observador participante, integrante da escola de samba, guarda-sacola etc. sendo mais do que um e menos do que vários (Law, 1999).

Se, por um lado, os não-humanos limitaram a movimentação do pesquisador na concentração e na avenida, por outro possibilitaram que ele tivesse experiência que somente a observação participante permitiria, ou seja, vivenciar as experiências dos pesquisados como se fosse um deles (Stacey, 1977). E isso teve impacto direto no trabalho original sobre a Escola de Samba. Tornar-se pesquisadorintegrante no dia do desfile, algo não planejado no protocolo da pesquisa, e acessar as experiências de ter de resolver problemas imprevistos com fantasias, empurrar enorme carro alegórico com problemas que o impediriam de entrar na avenida, coordenar os merendeiros por meio de sinais, além de se distrair com a empolgação do público, contribuiu para que o pesquisador compreendesse, de forma mais apurada, muito daquilo que ele acompanhou na preparação do carnaval: reuniões, ensaios na quadra, ensaios técnicos no sambódromo e visitas ao barracão, durante os meses anteriores ao desfile.

Apesar de termos destacado o papel dos não-humanos na prática da pesquisa, isso não significa dizer que eles possuem capacidade de agência independente dos humanos. O que há na verdade é uma cadeia de associação entre esses elementos (pesquisador, camisa, informante, sacolas, componentes de carro, só para citar alguns), embora eventualmente um ou outro possa se apresentar como mais significante em dados momentos, como no caso da camisa e das sacolas. Não defendemos aqui uma primazia dos não-humanos, em relação aos humanos na prática da pesquisa, como elementos determinantes para a configuração e/ou direcionamento da observação. Mas também entendemos que essa supremacia, quando aplicada aos humanos, pode ser ilusória. Pesquisar organizações, seja por meio da etnografia e emprego da observação ou por qualquer outro método, envolve lidar com a heterogeneidade do mundo social.

$\mathrm{Na}$ presente pesquisa, embora os não-humanos se tenham apresentado como "intrusos" e interferido diretamente no mecanismo de observação, não significa que eles não sejam bem-vindos. Ao contrário disso, associar-se a eles pode ser produtivo para o pesquisador, como comentamos anteriormente. Assim, alguns instrumentos de pesquisa, como micro-câmeras, GPS e câmeras fotográficas, podem facilitar de maneira significativa a observação e permitir a própria manutenção do observador a distância, preservando o que havia sido planejado, caso o distanciamento seja imprescindível para o desenvolvimento adequado da pesquisa. Trabalhos futuros poderiam explorar como estes elementos auxiliam e facilitam a tarefa de observação.

Por fim, algumas questões éticas podem ser levantadas para futuras reflexões: qual o limite da interferência do pesquisador, considerando que suas decisões podem gerar sérias consequências para os pesquisados? Ao ingressar como observador não-participante, até que ponto o pesquisador deve aceitar essas transformações, ou como lidar com elas, e assumir funções que, inicialmente, não lhe foram formalmente atribuídas? Como observou uma integrante da escola após o desfile: "Foi sua primeira vez na avenida e já te colocaram para trabalhar". Sugerimos ainda que os pesquisadores da área da administração comecem a levar mais a sério o papel dos não-humanos na prática da pesquisa de campo e na relação com o objeto estudado, uma vez que eles possuem participação ativa em suas atividades. 


\section{Artigo recebido em 08.05.2010. Aprovado em 20.09.2010.}

\section{Notas}

${ }^{1}$ Para mais detalhes sobre a prática de pesquisa e a participação de não-humanos nesse processo, ver Latour e Woolgar (1997), Latour, B. (2000). Ciência em ação: como seguir cientistas e engenheiros sociedade afora. São Paulo: UNESP, e Law (2004).

${ }^{2} \mathrm{O}$ setor de harmonia é responsável pelo desenvolvimento e colocação em prática da estrutura sobre a qual a produção do desfile se realizará, bem como pela condução das principais atividades relacionadas a este processo, garantindo, como o próprio nome revela, a harmonia no desfile. Este setor entra em ação efetivamente após a definição do samba-enredo da escola, que acontece por volta de setembro.

${ }^{3}$ Alegoria é uma subdivisão da harmonia responsável pelos carros alegóricos, que também são chamados de alegorias; daí o nome da subdivisão. Seus membros dão apoio aos coordenadores de carro alegórico, ajudando os componentes dos carros (ver nota 7), com suas fantasias, colocando-os nos seus lugares nos carros, dando informações sobre quem sairá em qual carro e coordenando os merendeiros (ver nota 6) na hora do desfile.

${ }^{4}$ Concentração é um local no sambódromo, onde os integrantes das escolas permanecem concentrados antes de iniciar o desfile. Neste espaço são posicionados os carros alegóricos, e os componentes das alas ficam aguardando a hora de entrar na avenida. Este é um momento de tensão, pois ali são feitos os últimos acertos tanto nas fantasias quanto nos carros alegóricos.

${ }^{5}$ Os membros do setor de harmonia têm por hábito referir-se uns aos outros como harmonia.

${ }^{6}$ Merendeiros são aqueles indivíduos responsáveis por empurrar os carros alegóricos no dia do desfile. São normalmente pessoas conhecidas dos harmonias ou foliões, que querem sair na avenida e são recrutados para exercer essa função. Geralmente recebem um valor monetário de mais ou menos $\mathrm{R} \$ 20,00$ para executarem essa atividade. Além de dinheiro recebem também uma merenda (lanche) antes do desfile começar. Daí o nome de merendeiro.

${ }^{7}$ Composições ou componentes de carro alegórico são aquelas pessoas que saem fantasiadas nas laterais dos carros.

${ }^{8}$ Pessoas com fantasias luxuosas que ficam em destaque no alto dos carros alegóricos.

${ }^{9}$ Barra de ferro que atravessa toda a parte de trás do carro e serve de apoio para os merendeiros empurrarem.

${ }^{10}$ A linha amarela no início da avenida demarca o local onde se inicia o desfile e os jurados já podem avaliar a escola.

${ }^{11}$ Buraco é um espaço grande, sem medida precisa e definida, que se forma entre as alas ou entre um carro alegórico e uma ala. Caso seja identificado pelos jurados, a escola perde pontos.

${ }^{12}$ Durante o desfile, os merendeiros são os indivíduos com menor status na avenida.

${ }^{13}$ Em uma das reuniões, o Diretor de Harmonia disse que os harmonias só curtem o carnaval e podem distrair-se no desfile das campeãs. No primeiro desfile os harmonias apenas devem trabalhar.

${ }^{14}$ Local amplo no final da avenida, onde as alas saem de sua formação original e os carros são estacionados até que todos os seus componentes desçam de seus lugares.

${ }^{15}$ Em uma entrevista com a informante da pesquisa, ela relatou que em desfiles anteriores a escola perdeu pontos por causa de pequenos detalhes nas fantasias.

\section{Referências}

Agar, M. (1980). The professional stranger: an informal introduction to ethnography. New York: Academic Press.

Atkinson, P., Coffey, A., Delamont, S., Lofland, J., \& Lofland, L. (Eds.). (2007). Handbook of Ethnography. London, Thousand Oaks, New Delhi: Sage Publications.

Bate, S. P. (1997). Whatever happened to organizational anthropology? A review of the field of organizational ethnography and anthropological studies. Human Relations, 50(9), 1147-1175. doi: 10.1177/001872679705000905 
Blackler, F., \& Engeström, Y. (Eds.). (2005). The rise of objects in the study of organizations [Special Issue]. Organization, 12(3), 307-461.

Bresler, R. (1997). A roupa surrada e o pai: etnografia de uma marcenaria. In F. P. Motta \& M. Caldas (Orgs.), Cultura organizacional e cultura brasileira (pp. 111-126). São Paulo: Atlas.

Callon, M., \& Law, J. (2003). On qualculation, agency and otherness. Lancaster: Centre for Science Studies, Lancaster University. Recuperado em 22 novembro, 2005, de http://www.lancs.ac.uk/fass/sociology/papers/callon-law-qualculation-agency-otherness.pdf

Carr, A., \& Downs, A. (2004). Transitional and quasi-objects in organization studies: viewing Enron from the object relations world of Winnicott and Serres. Journal of Organizational Change Management, 17(4), 352-364. doi: 10.1108/09534810410545119

Clifford, J. (2008). A experiência etnográfica: antropologia e literatura no século XX (3a ed.). Rio de Janeiro: Editora UFRJ.

Czarniawska, B. (2007). Shadowing and other techniques for doing fieldwork in modern societies. Liber: Copenhagen Business School Press.

Deegan, M. J. (2007). The Chicago school of etnography. In P. Atkinson, A. Coffey, S. Delamont, J. Lofland, \& L. Lofland (Eds.), Handbook of Ethnography (pp. 11-24). London, Thousand Oaks, New Delhi: Sage Publications.

Denzin, N. K., \& Lincoln, Y. S. (2000). Introduction: the discipline and practice of qualitative research. In N. K. Denzin \& Y. Lincoln (Eds.), Handbook of qualitative research (2a ed., pp. 145). Thousand Oaks: Sage Publications.

Downs, A., \& Hagemeijer, R. (Eds.). (2004). The sociology of objects: rediscovering the importance of objects in organizational life [Special Issue]. Journal of Organizational Change Management, 17(4), 337-424.

Emerson, R. M., Fretz, R. I., \& Shaw, L. L. (1995). Writing ethnographic fieldnotes. Chicago: University of Chicago Press.

Engeström, Y, \& Blackler, F. (2005). On the life of the object. Organization, 12(3), 307-330. doi: $10.1177 / 1350508405051268$

Flores-Pereira, M. T., \& Cavedon, N. R. (2009). Os bastidores de um estudo etnográfico: trilhando os caminhos teórico-empíricos para desvendar as culturas organizacionais de uma livraria de shopping center. Cadernos EBAPE.BR, 7(1), 144-160.

Goldwasser, M. J. (1975). O palácio do samba: estudo antropológico da escola de samba estação primeira de mangueira. Rio de Janeiro: Zahar Editores.

Hammersley, M. (1992). What's wrong with ethnography. New York: Routledge.

Hammersley, M., \& Atkinson, P. (1995). Ethnography: principles in practice. London: New York, Routledge.

Haraway, D. (1991). Simians, cyborgs, and women: the reinvention of nature. London: Free Association Books.

Haraway, D. (2006). Encounters with companion species: entangling dogs, baboons, philosophers, and biologists. Configurations, 14(1-2), 97-114. doi: 10.1353/con.0.0002

Knorr-Cetina, K. (1997). Sociality with objects: social relation in postsocial knowledge societies. Theory, Culture \& Society, 14(4), 1-30. doi: 10.1177/026327697014004001 
Kunda, G. (1992). Engineering culture: control and commitment in a high-tech corporation. Philadelphia: Temple University Press.

Latour, B. (1988). The pasteurization of France. Cambridge, Mass: Harvard University Press.

Latour, B. (1994). Jamais fomos modernos: ensaios de antropologia simétrica. Rio de Janeiro: Editora 34.

Latour, B. (1999). On recalling ANT. In J. Law \& J. Hassard (Eds.), Actor network theory and after (pp. 15-25). Oxford: Blackwell Publishers.

Latour, B. (2001). A esperança de pandora: ensaios sobre a realidade dos estudos científicos. São Paulo: EDUSC.

Latour, B. (2005). Reassembling the social: an introduction to actor-network theory. New York: Oxford University Press.

Latour, B., \& Woolgar, S. (1997). A vida de laboratório: a produção dos fatos científicos. Rio de Janeiro: Relume Dumará.

Law, J. (1991). Introduction: monsters, machines and sociotechnical relation. In J. Law (Ed.), A sociology of monsters: essays on power, technology and domination (pp. 1-33). London and New York: Routledge.

Law, J. (1997a). The manager and his powers. Lancaster: Centre for Science Studies, Lancaster University. Recuperado em 22 novembro, 2005, de http://www.lancs.ac.uk/fass/sociology/papers/law-manager-and-his-powers.pdf

Law, J. (1997b). Topology and the naming of complexity. Lancaster: Centre for Science Studies, Lancaster University. Recuperado em 22 novembro, 2005, de http://www.lancs.ac.uk/fass/sociology/papers/law-topology-and-complexity.pdf

Law, J. (1999). After ANT: complexity, naming and topology. In J. Law \& J. Hassard (Eds.), Actor network theory and after (pp. 1-14). Oxford: Blackwell Publishers.

Law, J. (2004). After method: mess in social science research. London, New York: Routledge.

Law, J., \& Urry, J. (2004). Enacting the social. Economy and Society, 33(3), 390-410. doi: $10.1080 / 0308514042000225716$

Linstead, S. (1993). From postmodern anthropology to deconstructive ethnography. Humam Relation, 46(1), 97-120. doi: 10.1177/001872679304600107

Malinowski, B. (1976). Os argonautas do pacífico ocidental: um relato do empreendimento e da aventura dos nativos nos arquipélagos da nova guiné melanésia. São Paulo: Abril. (Obra original publicada em 1922)

Michael, M. (2004). On making data social: heterogeneity in social practice. Qualitative Research, 4(5), 5-23. doi: 10.1177/1468794104041105

Mintzberg, H. (1971). Managerial work. Analyses from observation. Management Science, 18(2), 97110. doi: 10.1287/mnsc.18.2.B97

Mol, A. (2002). The body multiple: ontology in medical practice. Durham, NC: Duke University Press.

Norén, L., \& Ranerup, A. (2005). The Internet web portal as an enrolment device. In B. Czarniawska \& T. Hernes (Eds.), Actor-network theory and organizing (pp. 188-207). Malmo: Liber \& Copenhagen Business School Press. 
Orlikowski, W. J. (2007). Sociomaterial practices: exploring technology at work. Organization Studies, 28(9), 1435-1448. doi: 10.1177/0170840607081138

Queiroz, M. I. P. (1999). Carnaval brasileiro: o vivido e o mito. São Paulo: Brasiliense.

Rosen, M. (1991). Coming to terms with the field: understanding and doing organizational ethnography. Jornal of Management Studies, 28(1), 1-24.

Rubio, F. D. (2005). Re-pensando lo social: apuntes para la re-descripición de um nuevo objeto para la sociologia [Edição Especial]. Revista de Antropologia Iberoamericana, 1-29.

Schatzki, T. R., Knorr-Cetina, K., \& Savigny, E. von (Eds.). (2001). The practice turn in contemporary. London: Routledge.

Schinkel, W. (2004). "Inertia creeps", or a phenomenological perspective on objects in sociology. Journal of Organizational Change Management, 17(4), 396-407. doi: $10.1108 / 09534810410545146$

Schwartzman, H. B. (1993). Ethnography in organizations. London: SAGE Publications.

Scott, W. R. (1972). Field methods in the study or organizations. In J. G. March (Ed.), Handbook of organizations (pp. 412-440). Chicago: Rand McNally \& Company.

Spradley, J. P. (1979). The ethnographic interview. Belmont, CA: Wadsworth Group \& Thomson Learning.

Stacey, M. (1977). Methods of social research. Oxford: Pergamon Press.

Suchman, L. (2005). Affiliative objects. Organization, 12(3), 379-399. doi: $10.1177 / 1350508405051276$

Tureta, C., \& Alcadipani, R.. (2009). O objeto objeto na análise organizacional: a teoria ator-rede como método de análise da participação dos não-humanos no processo organizativo. Cadernos EBAPE.BR, 7(1), 48-65.

Van Maanen, J. (1975). Police socialization: a longitudinal examination of job attitudes in an urban police department. Administrative Science Quarterly, 20(2), 207-228. doi:10.2307/2391695

Whyte, W. F. (1955). Street corner society. Chicago: University Chicago Press. 